\title{
The Efficiency Adsorption of Ammonia Nitrogen, Phosphate and Basic Blue 3 by Fulvic Acid Decorated $\mathrm{Fe}_{3} \mathrm{O}_{4}$ Magnetic Nanocomposites
}

\author{
Min Wang ${ }^{1}$, Yuming Zheng ${ }^{1}$, Qiang $\mathrm{Li}^{2,3 *}$, Yizhuo $\mathbf{Q i}^{2}$, Xuan Liao ${ }^{2}$, Qingchun Fu${ }^{1}$ \\ ${ }^{1}$ State Key Laboratory of Eco-Hydraulic in Northwest Arid Region of China, Xi'an University of Technology, \\ 710048, Xi'an, PR China \\ ${ }^{2}$ School of Environmental Engineering, Wuhan Textile University, Wuhan 430073, PR China \\ ${ }^{3}$ Engineering Research Center for Clean Production of Textile Dyeing and Printing, Ministry of Education, \\ Wuhan 430073, China
}

Received: 13 September 2020

Accepted: 11 November 2020

\begin{abstract}
Magnetic nanocomposites have attracted much attention in the field of wastewater treatment due to their great advantages of fast and efficient removal and separation. Therefore, $\mathrm{Fe}_{3} \mathrm{O}_{4}$ magnetic nanocomposites coated with fulvic acid $\left(\mathrm{Fe}_{3} \mathrm{O}_{4} / \mathrm{FA}\right)$ were applied to remove ammonia nitrogen, phosphate and basic blue 3 (BB3) from the effluent. The performance of the adsorbents towards the pollutant removal under different contact time, $\mathrm{pH}$, ionic strength and temperatures were investigated. The whole process with adsorption kinetics and adsorption thermodynamics were also studied. The results showed that the adsorption equilibrium could be achieved in $180 \mathrm{~min}$. The high susceptibility of ammonia nitrogen, phosphorus and $\mathrm{BB} 3$ to the alternation of $\mathrm{pH}$, ionic strength and temperatures indicated that electrostatic interaction played a dominant role in the process. $\mathrm{Fe}_{3} \mathrm{O}_{4} / \mathrm{FA}$ exhibited excellent adsorption performance for ammonia nitrogen, phosphorus and BB3, and the $q_{\max }$ obtained by the Langmuir model were $106.21 \mathrm{mg} / \mathrm{g}, 116.81 \mathrm{mg} / \mathrm{g}$ and $203.54 \mathrm{mg} / \mathrm{g}$, respectively. Its adsorption performance remained constant in the treatment of ammonia nitrogen, phosphate and BB3 after consecutive 6 cycles. In practical wastewater treatment, $\mathrm{Fe}_{3} \mathrm{O}_{4} / \mathrm{FA}$ improved the removal of ammonia nitrogen and phosphate. Therefore, $\mathrm{Fe}_{3} \mathrm{O}_{4} / \mathrm{FA}$ magnetic nanocomposites have a promising application for wastewater treatment.
\end{abstract}

Keywords: magnetic nanocomposites, fulvic acid, ammonia nitrogen, phosphate, basic blue 3

*e-mail: qiangli@wtu.edu.cn 


\section{Introduction}

Wastewater containing nitrogen, phosphorus and dye from urban living and industrial development has put forward a great challenge to the environment. Once surplus nitrogen and phosphorus were discharged into wastewater, the aquatic organism would suffer breathing difficulties, weakened immunity and even mass mortality [1]. What's more, the high concentration of ammonia nitrogen enriched in organisms can be further converted into strong oxidation and carcinogenic nitrite, resulting in greater harm [2]. Excessive phosphorus content will lead to eutrophication of waters, rapid overgrowth of aquatic algae and the sharp decrease of water dissolved oxygen content. At the same time, eutrophication can also cause water odor, deteriorate the water quality, and increase the difficulty and cost of water treatment [3].

Dyeing wastewater with deep chromaticity and complex composition is harmful to the environment. Dyes own the characteristics of absorbing light, reducing the transparency of water, consuming a large number of dissolved oxygen, affecting aquatic organisms and microbial growth, and destroying the self-purification capacity of water. The aromatic polyphenyl ring derivatives produced by substituting hydrogen on the dye benzene ring to amine, nitro and halogen groups own high biotoxicity, and some of them even have malign effects as teratogenic, carcinogenic and mutagenic, etc. Besides, the dyeing wastewater may contain heavy metals, such as cuprum, chromium, lead and so on. These heavy metals with high toxicity are difficult to be degraded by organisms, which further aggravate heavy metal pollution and increase plants, animals, and human health risks $[4,5]$.

So far, different kinds of physical and chemical methods have been applied to removing nitrogen, phosphorus and dye in the wastewater treatment, such as adsorption, coagulation, oxidation, electrolysis, and biological treatment $[6,7]$. Compared with these methods, adsorption is a high-efficiency, economical and convenient method with good selectivity. Particularly, it presents practical application value in removing low concentration pollution. Many titanate nanotubes and polymer-based nanomaterials have excellent adsorption properties for nitrogen, phosphorus, dyes and organic pollutants [8-13]. However, the difficulty of recycling these materials after adsorption limited its application in water purification and remediation.

Magnetite particles $\left(\mathrm{Fe}_{3} \mathrm{O}_{4}\right)$, as a kind of highly magnetic nanomaterial, perfectly solved the problem of adsorbent recycling. $\mathrm{Fe}_{3} \mathrm{O}_{4}$ has been widely used in removing various pollutants for its good saturation magnetic strength and easiness of being re-collected with a magnet from water $[14,15]$. However, the pure $\mathrm{Fe}_{3} \mathrm{O}_{4}$ can be oxidized in air and easily aggregate in an aqueous solution. To solve the problem, fulvic acid (FA) was introduced to the surface of the magnetic particles as a protective agent. FA is an organic substance in the soil and water environment with many active sites on its surface for the complexation of pollutants. Hence, $\mathrm{Fe}_{3} \mathrm{O}_{4} /$ FA composites were made as a novel stable coreshell composite material. The composites not simply have the magnetic separation property but also have the multi-functional group characteristic of shell organics, showing good removal performance for pollutants [1619]. According to our previous study, the agglomeration of $\mathrm{Fe}_{3} \mathrm{O}_{4}$ nanoparticle could be significantly reduced and the dispersity of the composite was able to be improved in the water solution with the participation of FA [15].

Therefore, the performance of $\mathrm{Fe}_{3} \mathrm{O}_{4} / \mathrm{FA}$ composites in removing ammonia nitrogen, phosphate and basic blue 3 (BB3) under different environmental conditions, including ion strength, $\mathrm{pH}$ and temperature were discussed. Meanwhile, the reuse performance of $\mathrm{Fe}_{3} \mathrm{O}_{4} / \mathrm{FA}$ was studied for practical application.

\section{Material and Methods}

\section{Chemicals}

$\mathrm{FeCl}_{3} \cdot 6 \mathrm{H}_{2} \mathrm{O}, \mathrm{FeSO}_{4} \cdot 7 \mathrm{H}_{2} \mathrm{O}$, ammonium hydroxide, $\mathrm{NH}_{4} \mathrm{Cl}, \mathrm{NaCl}, \mathrm{HCl}, \mathrm{NaOH}$ and $\mathrm{KH}_{2} \mathrm{PO}_{4}$ were provided by China Chemical Reagent Co., LTD. The fulvic acid (FA) was purchased from Aldrich (Sigma-Aldrich, Steinheim, Germany). Basic blue 3 (BB3) was provided by Sinopharm Chemical Reagent Co. Ltd. (Shanghai, China). Ammonia nitrogen solution was prepared by dissolving $\mathrm{NH}_{4} \mathrm{Cl}$ with appropriate amounts of deionized water. Phosphate solution was prepared by dissolving $\mathrm{KH}_{2} \mathrm{PO}_{4}$ with appropriate amounts of deionized water. All of the chemical reagents used in experiments were analytical grade reagents.

\section{Preparation of Adsorbents}

$\mathrm{Fe}_{3} \mathrm{O}_{4} / \mathrm{FA}$ magnetic composites were prepared by the co-precipitation method [17,20-21]. The detailed procedures were as follows: dissolving $10.0 \mathrm{~g}$ of $\mathrm{FeCl}_{3} \cdot 6 \mathrm{H}_{2} \mathrm{O}$ and $8.0 \mathrm{~g}$ of $\mathrm{FeSO}_{4} \cdot 7 \mathrm{H}_{2} \mathrm{O}$ into $200 \mathrm{~mL}$ of distilled water and heated to $90^{\circ} \mathrm{C}$, then adding $20 \mathrm{~mL}$ of ammonium hydroxide and $1.0 \mathrm{~g}$ of FA immediately. The mixture would react for $1 \mathrm{~h}$ under the protection of nitrogen at $90^{\circ} \mathrm{C}$ and cooled to room temperature. The black precipitate at the bottom of the beaker was collected and washed by distilled water many times till $\mathrm{pH}$ reached neutral. Finally, colloidal samples were left in a vacuum drier to dry and then ground for subsequent use.

\section{Adsorption Procedures}

All adsorption experiments were conducted in $10 \mathrm{~mL}$ polyethylene centrifuge tubes. In detail, the suspension liquid of $\mathrm{Fe}_{3} \mathrm{O}_{4} / \mathrm{FA}$ adsorbents and background electrolyte solution $\mathrm{NaCl}$ were mixed in advance. The stock solution of ammonia 
nitrogen, phosphate and $\mathrm{BB} 3$ was added to make the concentration of each component reach the preset value, respectively. $\mathrm{pH}$ was adjusted to the desired value with the trace amount of $\mathrm{HCl}$ and $\mathrm{NaOH}$ solution at the concentration of $0.1 \mathrm{~mol} / \mathrm{L}$. The centrifuge tube with suspension was oscillated at $150 \mathrm{rpm}$ to make the adsorption process reach equilibrium and then the supernatant was obtained by solid-liquid separation with the magnet, and the residual concentration of the pollutant was measured by spectrophotometer. In the desorption experiments, $500 \mathrm{~mL}$ of solution containing $0.01 \mathrm{~mol} / \mathrm{L} \mathrm{NaCl}$ with $50 \mathrm{mg} / \mathrm{L}$ ammonia nitrogen, phosphorus and $\mathrm{BB} 3$ were respectively placed into three beakers and adding $0.5 \mathrm{~g} / \mathrm{L} \mathrm{Fe}_{3} \mathrm{O}_{4} / \mathrm{FA}$ into them. The suspension was mechanically stirred for 24 hours before magnetic separation. The solid part was repeatedly rinsed with $0.1 \mathrm{~mol} / \mathrm{L} \mathrm{HCl}$ or $\mathrm{NaOH}$ solution until no contaminants were detected in the eluent. Last, the residual $\mathrm{Fe}_{3} \mathrm{O}_{4} / \mathrm{FA}$ was collected and dried at $60^{\circ} \mathrm{C}$. Six times adsorption-desorption experiments were carried out and the adsorption rates of pollutants on magnetic material were subsequently measured.

To study the adsorption properties of the composites in mixed effluent, the industrial wastewater in the Shaoxing area was referred to prepare the simulated wastewater. It contains $10 \mathrm{mg} / \mathrm{L} \mathrm{Ni(II),} 10 \mathrm{mg} / \mathrm{L} \mathrm{Pb}$ (II), $50 \mathrm{mg} / \mathrm{L}$ ammonia nitrogen, $50 \mathrm{mg} / \mathrm{L}$ phosphate, $50 \mathrm{mg} / \mathrm{L} \mathrm{BB} 3$ and $0.01 \mathrm{~mol} / \mathrm{L} \mathrm{NaCl}$ (as background electrolyte). $250 \mathrm{~mL}$ simulated wastewater was added into a $500 \mathrm{~mL}$ beaker following the above-mentioned methods at pH 5.0 to carry out static batch experiment.

\section{Analytical Methods}

The sorption rate and adsorption capacity of the contaminants on the magnetic composites were calculated by (1) and (2):

$$
\text { Sorption rate }(\%)=\left(C_{0}-C_{\text {eq }}\right) / C_{0} \times 100 \%
$$

$$
\text { Adsorption capacity } q_{\mathrm{e}}(\mathrm{mg} / \mathrm{g})=\left(C_{0}-C_{\mathrm{eq}}\right) \cdot V / m
$$

...where $C_{0}(\mathrm{mg} / \mathrm{L})$ was the initial concentration of the pollutants, $C_{\mathrm{eq}}(\mathrm{mg} / \mathrm{L})$ was the equilibrium concentration of the pollutants, $V(\mathrm{~L})$ was the volume of solution, and $m$ (g) is the weight of the adsorbents used. All experiments were duplicated and the average standard deviation of the duplicated experiments was less than $\pm 5.0 \%$.

\section{Results and Discussion}

\section{Effect of Contact Time}

Fig. 1 described the adsorption kinetics curve of ammonia nitrogen, phosphate and BB3 on $\mathrm{Fe}_{3} \mathrm{O}_{4} / \mathrm{FA}$ composites. With the contact time increased from $10 \mathrm{~min}$ to $180 \mathrm{~min}$, the sorption rate (\%) of

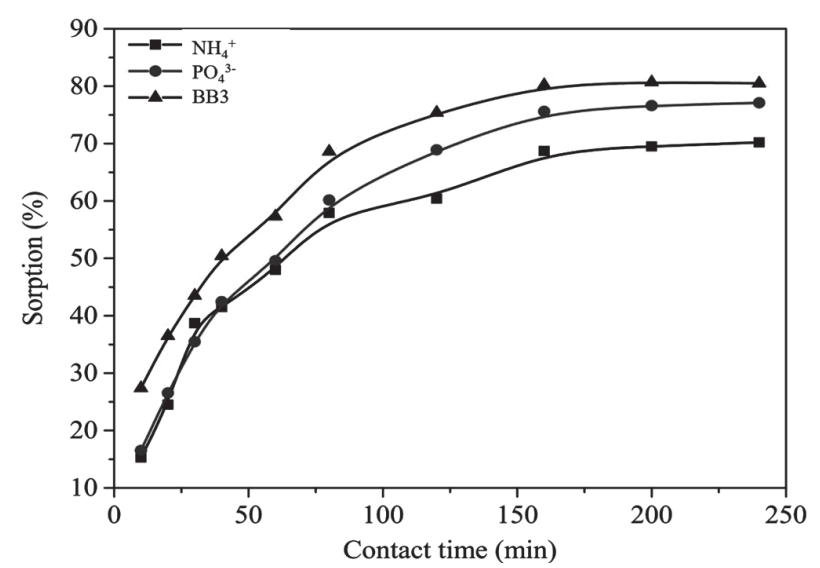

Fig. 1. Effect of contact time on the adsorption of ammonia nitrogen, phosphate and $\mathrm{BB} 3$ by $\mathrm{Fe}_{3} \mathrm{O}_{4} / \mathrm{FA}(\mathrm{pH}=5.0, \mathrm{~T}=298 \mathrm{~K}$, $\mathrm{m} / \mathrm{V}=0.5 \mathrm{~g} / \mathrm{L}$, the initial concentration of ammonia nitrogen, phosphate and BB3 were $50 \mathrm{mg} / \mathrm{L}$ ).

ammonia nitrogen rise from $15 \%$ to $70 \%$ and attained adsorption equilibrium. The adsorption tendency of phosphate and BB3 were analogous to ammonia nitrogen's curve, reaching the peak value at $180 \mathrm{~min}$. The adsorption kinetics of ammonia nitrogen, phosphate and BB3 achieved equilibrium in just $180 \mathrm{~min}$, which confirmed that the removal mechanism of the three pollutants on $\mathrm{Fe}_{3} \mathrm{O}_{4} / \mathrm{FA}$ was essentially chemisorption.

\section{Effect of $\mathrm{pH}$ and Ionic Strength}

The adsorption of ammonia nitrogen, phosphate and $\mathrm{BB} 3$ on $\mathrm{Fe}_{3} \mathrm{O}_{4} / \mathrm{FA}$ composites in different $\mathrm{pH}$ and ionic strengths were respectively shown in Fig. 2. As shown in Fig. 2a) and Fig. 2b), the sorption rate (\%) of ammonia nitrogen, phosphate gradually decreased with the increase of $\mathrm{pH}$ value, indicating that the alternative of the solution from acidic to alkaline was not conducive to the removal of ammonia nitrogen and phosphate. The zero charge point of the composite was 2.2 in our previous study [15]. At $\mathrm{pH}>3.0$, the functional group sites on its surface were negatively charged due to deprotonation $\mathrm{SOH} \Leftrightarrow \mathrm{SO}^{-}+\mathrm{H}^{+}$, and the electronegativity gradually increased with the increase of $\mathrm{pH}$ value. Ammonia nitrogen and phosphorus are usually electronegative which makes it hard to bond to the surface of the composites for the same electrical properties and leads to the dropping adsorption rate as the $\mathrm{pH}$ value goes up. The adsorption of BB3 has the opposite trend comparing with ammonia nitrogen and phosphorus (Fig. 2c). BB3 is positively charged in a wide $\mathrm{pH}$ range. With the increase of $\mathrm{pH}$, the charge attraction of these forms and the surface sites of $\mathrm{Fe}_{3} \mathrm{O}_{4} / \mathrm{FA}$ composite gradually increased, leading to the increase of adsorption rate. These experimental phenomena indicated that the electrostatic interaction was the dominant adsorption mechanism [22-25]. 

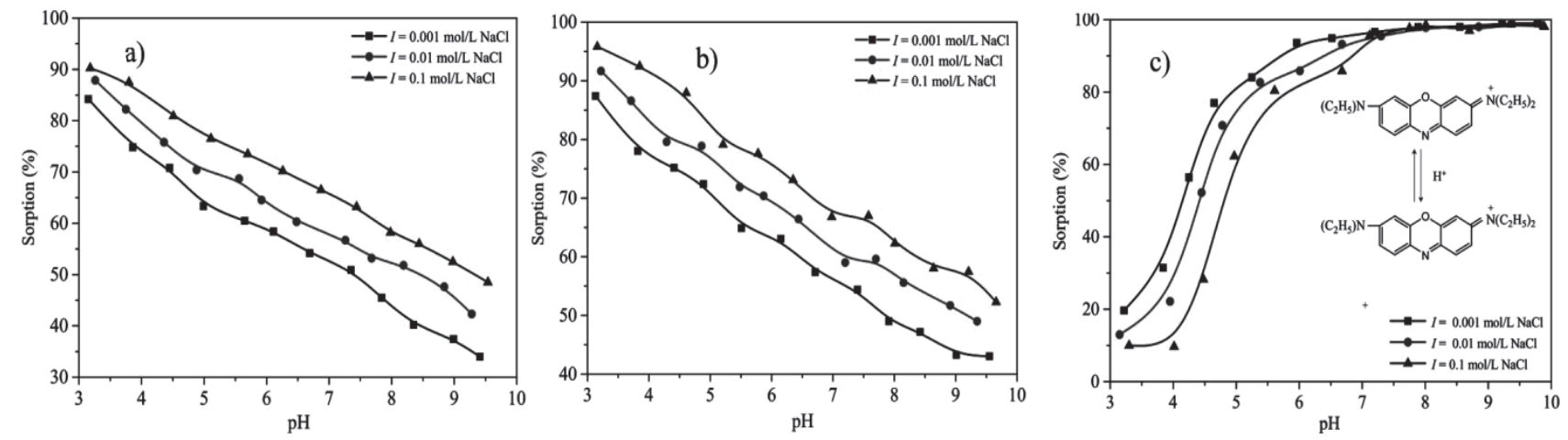

Fig. 2. Effect of $\mathrm{pH}$ and ionic strength on the adsorption of a) nitrogen; b) phosphorus; c) $\mathrm{BB} 3$ by $\mathrm{Fe}_{3} \mathrm{O}_{4} / \mathrm{FA}(T=298 \mathrm{~K}, \mathrm{~m} / \mathrm{V}=0.5 \mathrm{~g} / \mathrm{L}$, $C_{\mathrm{NH} 4}^{+}, C_{\text {phosphorus }}$ and $\left.C_{\mathrm{BB} 3}=50 \mathrm{mg} / \mathrm{L}\right)$.

\section{Sorption Isotherms}

To further investigate the adsorption mechanism, sorption isotherms of $\mathrm{Fe}_{3} \mathrm{O}_{4} / \mathrm{FA}$ composites on ammonia nitrogen, phosphorus and BB3 were depicted in Fig. 3. We can see that the sorption of ammonia nitrogen and phosphorus increased with the increasing temperature, indicating the whole adsorption process of ammonia nitrogen and phosphorus was endothermic. The sorption of BB3 decreased with the increasing temperature, suggesting the adsorption process of BB3 was exothermic. The Langmuir model and Freundlich model were applied to simulate the process. All of the parameters were listed in Table 1-3.

Compared with the correlation coefficient $\left(R^{2}\right)$, the Langmuir model fitted better than the Freundlich model. The results proved that the surface of $\mathrm{Fe}_{3} \mathrm{O}_{4} / \mathrm{FA}$ composites was relatively uniform, and chemisorption was the main removal mechanism of ammonia nitrogen, phosphorus and BB3 pollutants. The $q_{\max }$ obtained by the Langmuir model for ammonia nitrogen and phosphorus at $328 \mathrm{~K}$ were $106.21 \mathrm{mg} / \mathrm{g}$ and $116.81 \mathrm{mg} / \mathrm{g}$, respectively. The $q_{\max }$ obtained by the Langmuir model for BB3 at $298 \mathrm{~K}$ were $203.54 \mathrm{mg} / \mathrm{g}$. Under the condition of the above three temperature, the $q_{e}$ in the experiment were smaller than the $q_{\max }$ obtained by the Langmuir model fitting. This suggested that the unsaturated monolayer adsorption of ammonia nitrogen, phosphorus and $\mathrm{BB} 3$ on $\mathrm{Fe}_{3} \mathrm{O}_{4} /$ FA. The $n$ value of the experimental results of the Freundlich model was between 0 and 1 , indicating that the adsorption of ammonia nitrogen, phosphorus and BB3 on $\mathrm{Fe}_{3} \mathrm{O}_{4} / \mathrm{FA}$ composite was a spontaneous nonlinear process.

\section{Regeneration}

The reuse performance of the adsorbents is a key indicator to evaluate the potential application of the adsorbents in practical wastewater treatment. Therefore, it is imperative to explore the reuse performance of $\mathrm{Fe}_{3} \mathrm{O}_{4} / \mathrm{FA}$ composites. Considering the $\mathrm{pH}$ effect on the removal of the three pollutants, we adopted $0.1 \mathrm{M}$ of $\mathrm{NaOH}$ solution as the eluent of ammonia nitrogen and phosphorus, and $0.1 \mathrm{M}$ of $\mathrm{HCl}$ solution as the eluent of BB3. After being regenerated, the composites were used to finish the subsequent removal experiment. The sorption rates (\%) of the three pollutants on $\mathrm{Fe}_{3} \mathrm{O}_{4} / \mathrm{FA}$ composites almost stayed the same after six successive adsorption-desorption cycles (Fig. 4). The result
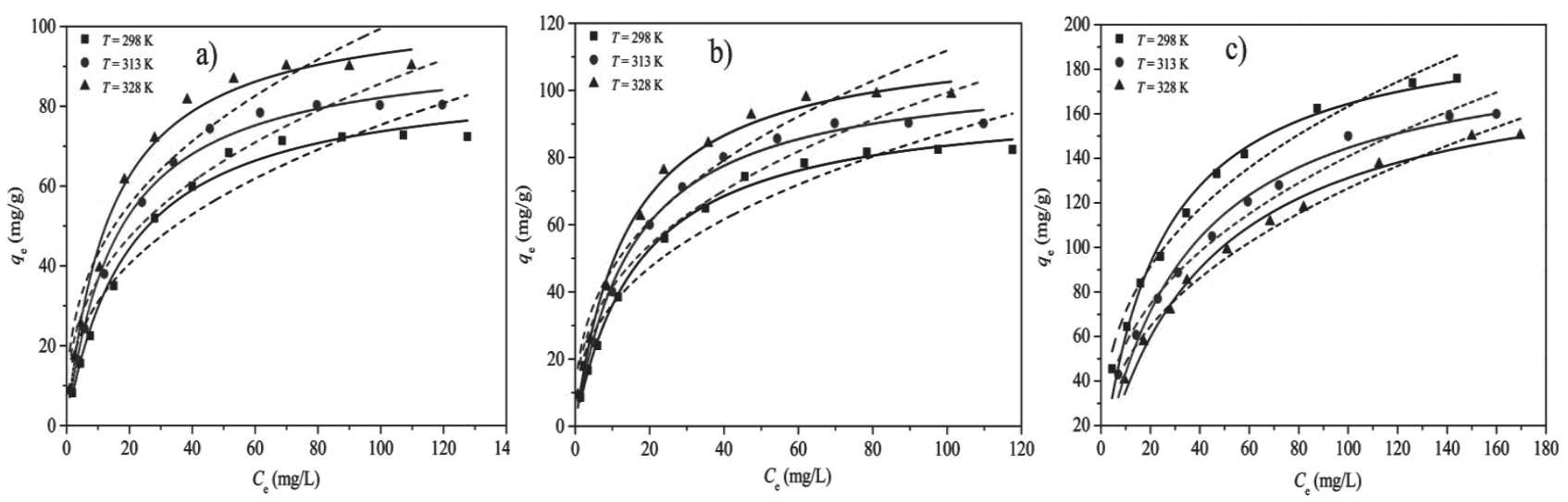

Fig. 3. Adsorption isotherms of a) ammonia nitrogen; b) phosphorus; c) $\mathrm{BB} 3$ on $\mathrm{Fe}_{3} \mathrm{O}_{4} / \mathrm{FA}$ (solid lines denote the fit curves of Langmuir model and dash lines denote the fit curves of Freundlich model, $\mathrm{pH}=5.0, \mathrm{~m} / \mathrm{V}=0.5 \mathrm{~g} / \mathrm{L}, \mathrm{I}=0.01 \mathrm{~mol} / \mathrm{L} \mathrm{NaCl}$ ). 
Table 1. Parameters of the Langmuir and Freundlich models for the adsorption of ammonia nitrogen on $\mathrm{Fe}_{3} \mathrm{O}_{4} / \mathrm{FA}$.

\begin{tabular}{|c|c|c|c|c|}
\hline \multicolumn{2}{|c|}{ Correlation parameters } & $T=298 \mathrm{~K}$ & $T=313 \mathrm{~K}$ & $T=328 \mathrm{~K}$ \\
\hline \multirow{4}{*}{ Langmuir } & $q_{\max }(\mathrm{mg} / \mathrm{g})$ & 88.30 & 95.32 & 106.21 \\
\cline { 2 - 5 } & $b(\mathrm{~L} / \mathrm{mg})$ & 0.050 & 0.062 & 0.072 \\
\cline { 2 - 5 } & $R^{2}$ & 0.990 & 0.993 & 0.990 \\
\hline \multirow{3}{*}{ Freundlich } & $K_{\mathrm{F}}\left(\mathrm{mg}^{1-\mathrm{n}} \cdot \mathrm{L}^{\mathrm{n}} / \mathrm{g}\right)$ & 12.78 & 15.58 & 18.61 \\
\cline { 2 - 5 } & $\mathrm{n}$ & 0.385 & 0.370 & 0.418 \\
\cline { 2 - 5 } & $\mathrm{R}^{2}$ & 0.914 & 0.917 & 0.364 \\
\hline
\end{tabular}

Table 2 Parameters of the Langmuir and Freundlich models for the adsorption of phosphorus on $\mathrm{Fe}_{3} \mathrm{O}_{4} / \mathrm{FA}$.

\begin{tabular}{|c|c|c|c|c|}
\hline \multicolumn{2}{|c|}{ Correlation parameters } & $T=298 \mathrm{~K}$ & $T=313 \mathrm{~K}$ & $T=328 \mathrm{~K}$ \\
\hline \multirow{4}{*}{ Langmuir } & $q_{\max }(\mathrm{mg} / \mathrm{g})$ & 97.87 & 107.39 & 116.81 \\
\cline { 2 - 5 } & $b(\mathrm{~L} / \mathrm{mg})$ & 0.058 & 0.065 & 0.071 \\
\cline { 2 - 5 } & $\mathrm{R}^{2}$ & 0.996 & 0.994 & 0.995 \\
\hline \multirow{3}{*}{ Freundlich } & $K_{\mathrm{F}}\left(\mathrm{mg}^{1-\mathrm{n}} \cdot \mathrm{L}^{\mathrm{n}} / \mathrm{g}\right)$ & 14.98 & 17.30 & 0.377 \\
\cline { 2 - 5 } & $\mathrm{n}$ & 0.383 & 0.921 & 0.933 \\
\hline
\end{tabular}

Table 3 Parameters of the Langmuir and Freundlich models for the adsorption of $\mathrm{BB} 3$ on $\mathrm{Fe}_{3} \mathrm{O}_{4} / \mathrm{FA}$.

\begin{tabular}{|c|c|c|c|c|}
\hline \multicolumn{2}{|c|}{ Correlation parameters } & $T=298 \mathrm{~K}$ & $T=313 \mathrm{~K}$ & $T=328 \mathrm{~K}$ \\
\hline \multirow{4}{*}{ Langmuir } & $q_{\max }(\mathrm{mg} / \mathrm{g})$ & 203.54 & 194.82 & 187.28 \\
\cline { 2 - 5 } & $b(\mathrm{~L} / \mathrm{mg})$ & 0.042 & 0.029 & 0.023 \\
\cline { 2 - 5 } & $\mathrm{R}^{2}$ & 0.989 & 0.984 & 0.986 \\
\hline \multirow{3}{*}{ Freundlich } & $K_{\mathrm{F}}\left(\mathrm{mg}^{1-\mathrm{n}} \cdot \mathrm{L} / \mathrm{g}\right)$ & 31.06 & 22.84 & 18.43 \\
\cline { 2 - 5 } & $\mathrm{n}$ & 0.360 & 0.395 & 0.418 \\
\cline { 2 - 5 } & $\mathrm{R}^{2}$ & 0.950 & 0.948 & 0.954 \\
\hline
\end{tabular}

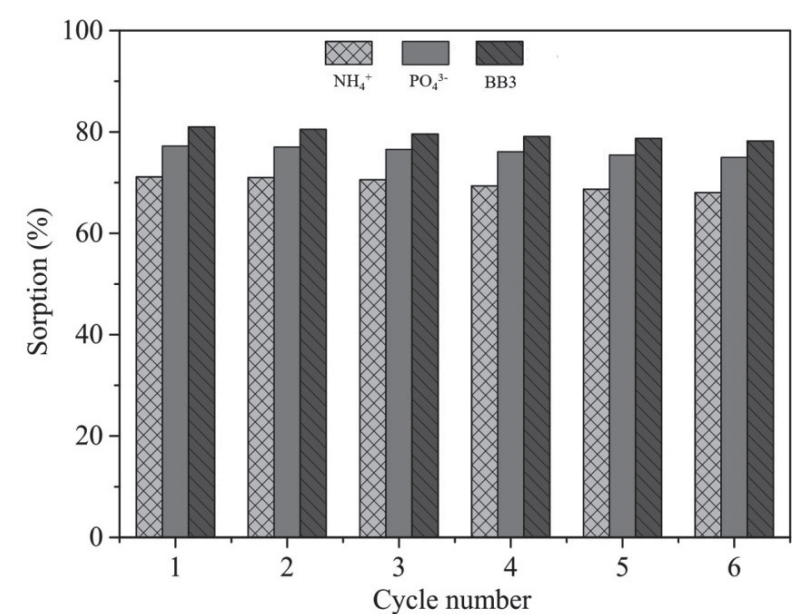

Fig. 4. The reuse performance of $\mathrm{Fe}_{3} \mathrm{O}_{4} / \mathrm{FA}$ for ammonia nitrogen, phosphorus and $\mathrm{BB} 3$ removal $(\mathrm{pH}=5.0, \mathrm{~T}=298 \mathrm{~K}$, $\mathrm{m} / \mathrm{V}=0.5 \mathrm{~g} / \mathrm{L}, \mathrm{I}=0.01 \mathrm{~mol} / \mathrm{L} \mathrm{NaCl}$, the concentration of $\mathrm{NH}_{4}^{+}$, $\mathrm{PO}_{4}^{3-}$ and BB3 were $50 \mathrm{mg} / \mathrm{L}$ ). showed excellent reused performance of the magnetic composites.

\section{Removal Performance in Mixed Wastewater}

In order to assess the practical potential of $\mathrm{Fe}_{3} \mathrm{O}_{4} / \mathrm{FA}$ composites in sewage treatment, the simulated wastewater was prepared for further study on the removal performance of the adsorbents. We made a comparison between the sorption rate (\%) of each contaminated component in the multi-solute system and the corresponding single-solute system to obtain the removal efficiency of the composites. As shown in Fig. 5, we found that the sorption rates (\%) of Ni(II), $\mathrm{Pb}(\mathrm{II})$ and $\mathrm{BB} 3$ in simulated wastewater by $\mathrm{Fe}_{3} \mathrm{O}_{4} / \mathrm{FA}$ were lower than those of the corresponding singlecomponent system, while the removal of ammonia 


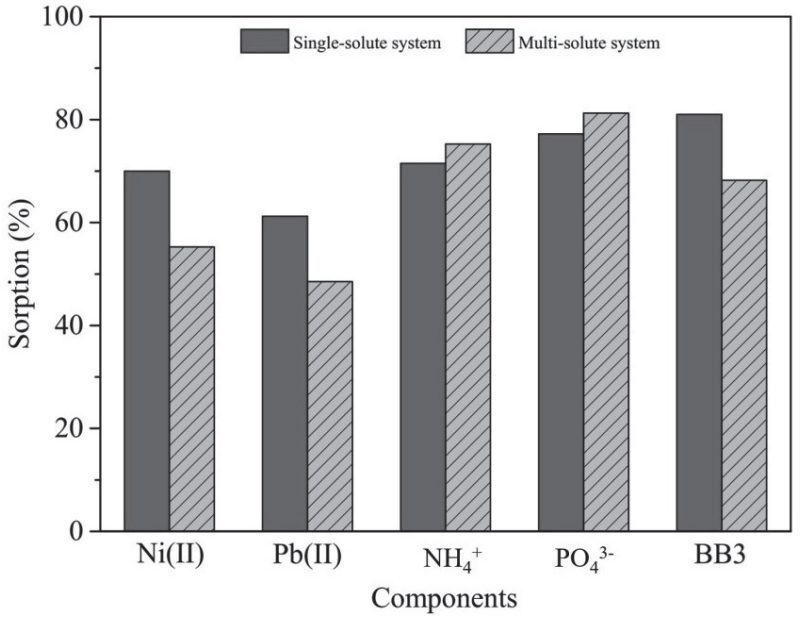

Fig. 5. The adsorption performance of $\mathrm{Fe}_{3} \mathrm{O}_{4} / \mathrm{FA}$ in simulation wastewater with multiple pollutant components $(\mathrm{pH}=5.0$, $\mathrm{T}=298 \mathrm{~K}, \mathrm{~m} / \mathrm{V}=0.5 \mathrm{~g} / \mathrm{L}, 10 \mathrm{mg} / \mathrm{L} \mathrm{Ni}(\mathrm{II}), 10 \mathrm{mg} / \mathrm{L} \mathrm{Pb}(\mathrm{II})$, $\mathrm{I}=0.01 \mathrm{~mol} / \mathrm{L} \mathrm{NaCl}$, the concentration of $\mathrm{NH}_{4}^{+}, \mathrm{PO}_{4}^{3-}$ and $\mathrm{BB} 3$ were $50 \mathrm{mg} / \mathrm{L}$ ).

nitrogen and phosphorus were higher than those of the corresponding single-component system. The results were possibly derived from interaction among multiple components, which influenced electrostatic and complexation between pollutants and adsorbents [26]. Generally, $\mathrm{Fe}_{3} \mathrm{O}_{4} / \mathrm{FA}$ composites showed strong ability in the removal of the five pollutants in mixed wastewater.

\section{Conclusions}

In the study, we found that the adsorption of $\mathrm{Fe}_{3} \mathrm{O}_{4} / \mathrm{FA}$ on ammonia nitrogen, phosphorus and BB3 could achieve equilibrium in $180 \mathrm{~min}$. As the ionic strength increased, the adsorbability of ammonia nitrogen and phosphorus was improved, but the adsorption of BB3 was inhibited. The results indicated that electrostatic binding was the dominant adsorption mechanism in the process. The $q_{\max }$ obtained by the Langmuir model for ammonia nitrogen, phosphorus and BB3 were $106.21 \mathrm{mg} / \mathrm{g}, 116.81 \mathrm{mg} / \mathrm{g}$ and $203.54 \mathrm{mg} / \mathrm{g}$, respectively. The adsorption capacity for ammonia nitrogen and phosphorus increased with the increasing temperature, indicating that the removal process was an endothermic process. The opposite phenomenon was found for the adsorption of BB3, suggesting the removal process of $\mathrm{BB} 3$ was an exothermic process. The adsorption process matched better with the Langmuir model which revealed that the surface of the composites was relatively uniform and chemisorption was the major removal mechanism. Ammonia nitrogen, phosphorus and BB3 occurred unsaturated monolayer adsorption in the surface of the composites, which belonged to spontaneous process. The removal of ammonia nitrogen and phosphorus were higher than those of the corresponding single-component system, while the removal of $\mathrm{BB} 3$ was lower than those of the corresponding single-component system. The experimental phenomenon probably resulted from the interaction among multiple components and affected electrostatic interaction and complexation between those pollutants and adsorbents. Furthermore, the adsorption of ammonia nitrogen, phosphorus and BB3 on $\mathrm{Fe}_{3} \mathrm{O}_{4} / \mathrm{FA}$ remained constant after six adsorptiondesorption cycles, showing excellent regeneration capacity.

\section{Acknowledgements}

We gratefully acknowledge the generous support provided by the "National Natural Science Foundation of China (51908432, 51809211)", the "Scientific Research Program Funded by Shaanxi Provincial Education Department (Program No.20JY045)", the "Natural Science Foundation of Shaanxi Province (2019JQ-745)", the "Natural Science Foundation of Hubei Province (2018CFB397)" and the "China Postdoctoral Science Foundation (2018M633548)".

\section{Conflict of Interest}

The authors declare no conflict of interest.

\section{References}

1. CHENG Q., LI H., XU Y., CHEN S., LI J. Study on the adsorption of nitrogen and phosphorus from biogas slurry by NaCl-modified zeolite. Plos One 12, e0176109, 2017.

2. YOUSFI I., SALEM H.B., AOUADI D., ABIDI S. Effect of sodium chloride, sodium sulfate or sodium nitrite in drinking water on intake, digestion, growth rate, carcass traits and meat quality of Barbarine lamb. Small Ruminant Research 143, 43, 2016.

3. LIU B., LIU LEI, LI WEI. Effective removal of phosphorus from eutrophic water by using cement. Environmental Research 183, 109218, 2020.

4. VARJANI S., RAKHOLIYA P., NG H.Y., YOU S., TEIXEIRA J.A. Microbial degradation of dyes: An overview. Bioresource Technology 314, 123728, 2020.

5. LI Q., WANG M., YUAN X., LI D., XU H., SUN L., PAN F., XIA D. Study on the adsorption and desorption performance of magnetic resin for Congo red. Environmental Technology 2, 1, 2019.

6. LI M., ZHANG Z., LI Z., WU H. Removal of nitrogen and phosphorus pollutants from water by $\mathrm{FeCl}_{3}$-impregnated biochar. Ecological Engineering 149, 105792, 2020.

7. ZHAO Y., ZHAO Z., SONG X., JIANG X., WANG Y., CAO X., SI Z., PAN F. Effects of nZVI dosing on the improvement in the contaminant removal performance of constructed wetlands under the dye stress. Science of the Total Environment 703, 134789, 2019.

8. ALI M.B., WANG F., BOUKHERROUB R., XIA M. High performance of phytic acid-functionalized spherical polyphenylglycine particles for removal of heavy metal ions. Applied Surface Science 518, 146206, 2020. 
9. DUAN J., JI H., XU T., PAN F., LIU X., LIU W., ZHAO D. Simultaneous adsorption of uranium(VI) and 2-chlorophenol by activated carbon fiber supported/ modified titanate nanotubes (TNTs/ACF): Effectiveness and synergistic effects. Chemical Engineering Journal 406, 126752, 2021.

10. YANG S., CHEN C., CHEN Y., LI J., WANG D., WANG $\mathrm{X}$., HU W. Competitive adsorption of $\mathrm{Pb}(\mathrm{II}), \mathrm{Ni}(\mathrm{II})$ and $\mathrm{Sr}(\mathrm{II})$ ions on graphene oxides: a combined experimental and theoretical study. ChemPlusChem 80, 480, 2015.

11. JI H., WANG T., HUANG T., LAI B., LIU W. Adsorptive removal of ciprofloxacin with different dissociated species onto titanate nanotubes. Journal of Cleaner Production 278, 123924, 2020.

12. SHENG G., SHEN R., DONG H., LI Y. Colloidal diatomite, radionickel and humic substance interaction: A combined batch, XPS and EXAFS investigation. Environmental Science and Pollution Research 20, 3708, 2013.

13. AI P.L., ARIS A.Z. A review on economically adsorbents on heavy metals removal in water and wastewater. Reviews in Environmental Science and Bio/Technology 13, 163, 2014.

14. HUANG S., CHEN D. Rapid removal of heavy metal cations and anions from aqueous solutions by an aminofunctionalized magnetic nano-adsorbent. Journal of Hazardous Materials 163, 174, 2009.

15. FU Q., ZHOU X., XU L., HU B. Fulvic acid decorated $\mathrm{Fe}_{3} \mathrm{O}_{4}$ magnetic nanocomposites for the highly efficient sequestration of $\mathrm{Ni}$ (II) from an aqueous solution. Journal of Molecular Liquids 208, 92, 2015.

16. PENG L., QIN P., LEI M., ZENG Q., SONG H., YANG J., SHAO J., LIAO B., GU J. Modifying $\mathrm{Fe}_{3} \mathrm{O}_{4}$ nanoparticles with humic acid for removal of Rhodamine B in Water. Journal of Hazardous Materials 209-210, 193, 2012.

17. LIU J.F., ZHAO Z.S., JIANG G.B. Coating $\mathrm{Fe}_{3} \mathrm{O}_{4}$ magnetic nanoparticles with humic acid for high efficient removal of heavy metals in water. Environmental Science \& Technology 42, 6949, 2008.
18. KAUR M., ZHANG H., MARTIN L., TODD T., QIANG Y. Conjugates of magnetic nanoparticle-actinide specific chelator for radioactive waste separation. Environmental Science \& Technology 47, 11942, 2013.

19. REDDY D.H.K., LEE S.M. Application of magnetic chitosan composites for the removal of toxic metal and dyes from aqueous solutions. Advances in Colloid and Interface Science 201-202, 68, 2013.

20. HAJIZADEH Z., VALADI K., REZA T.L., MALEKI A. Convenient $\mathrm{Cr}$ (VI) removal from aqueous samples: executed by a promising clay-based catalytic system, magnetized by $\mathrm{Fe}_{3} \mathrm{O}_{4}$ nanoparticles and functionalized with humic acid. ChemistrySelect 5, 2441, 2020.

21. PENG L., QIN P., LEI M., ZENG Q., SONG H., YANG J., SHAO J., LIAO B., GU J. Modifying $\mathrm{Fe}_{3} \mathrm{O}_{4}$ nanoparticles with humic acid for removal of Rhodamine $\mathrm{B}$ in Water. Journal of Hazardous Materials 209-210, 193, 2012.

22. NEWCOMBE G., DRIKAS M. Adsorption of NOM activated carbon: electrostatic and non-electrostatic effects. Carbon 35, 1239, 1997.

23. ALBERGHINA G., BIANCHINI R., FICHERA M., FISICHELLA S. Dimerization of Cibacron blue F3GA and other dyes: influence of salts and temperature. Dyes Pigments 46, 129, 2000.

24. GERMAN-HEINS J., FLURY M. Sorption of brilliant blue FCF in soils as affected by $\mathrm{pH}$ and ionic strength. Geoderma 97, 87, 2000.

25. PENG X., LUAN Z., ZHANG H. Montmorillonite-Cu(II)/ $\mathrm{Fe}(\mathrm{III})$ oxides magnetic material as adsorbent for removal of humic acid and its thermal regeneration. Chemosphere 63, 300, 2006.

26. FU Q., HU B., ZHOU X., HU Q., SHENG, J. Impact of key geochemical parameters on the attenuation of $\mathrm{Pb}$ (II) from water using a novel magnetic nanocomposite: fulvic acid-coated magnetite nanoparticles. Desalination and Water Treatment 57, 26063, 2016. 